
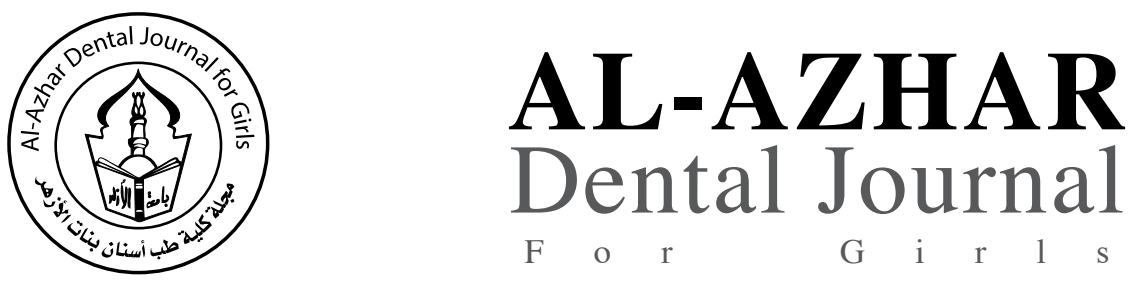

The Official Publication of The Faculty of Dental Medicine For Girls,

Al-Azhar University Cairo, Egypt.

ADJ-for Grils, Vol. 4, No. 1, January (2017) — PP. 1:7

\title{
Dentin Bond Strength Evaluation of Three Root Canal Sealers with Cold Gutta-Percha Lateral Obturation Technique: Push-Out Test Study
}

\author{
Mohammed E Rokaya ${ }^{(1)}$, Fahd M Hadhoud ${ }^{(1)}$ and MoatazBellah A Alkhawas ${ }^{(2)}$
}

Codex : 01/1701

dentaljournal.forgirls@yahoo.com

\begin{abstract}
Aim: This study was designed to evaluate dentin bond strength by push-out test of three root canal sealers (IRoot SP, AH Plus, and MTA Fillapex endodontic sealers) with cold gutta-percha lateral obturation technique using push-out test. Methods: A total of 57 human freshly extracted mandibular premolar teeth for orthodontic reason were used in this study. All samples were decoronated $16 \pm 1 \mathrm{~mm}$ from the apex and prepared using step-back technique up to master apical file \# 40. The specimens were divided randomly into three groups (19 teeth each) according to the type of sealers used; Group 1(IRoot SP), Group 2(AH Plus sealer), and Group 3 (MTA Fillapex sealer). Each group was obturated with cold gutta-percha lateral obturation technique. The specimens were incubated for 7 days at $37^{\circ} \mathrm{C}$ with $100 \%$ humidity. Three sections of $2 \mathrm{~mm}$ thickness were obtained at 3,7 and $11 \mathrm{~mm}$ from the apex to represent apical, middle and coronal third respectively. The push-out bond strength was determined for each root slice. Values were recorded, tabulated for each group and statistically analyzed. Results: IRoot SP showed the highest mean value of push-out bond strength (7.3 \pm 0.2$)$, followed by AH Plus $(6.8 \pm 0.1)$ while MTA Fillapex showed the lowest mean value of push-out bond strength (2.9 \pm 0.3$)$. Conclusions: IRoot SP and AH plus sealers had greater resistance to push-out than MTA Fillapex sealer.
\end{abstract}

\section{INTRODUCTION}

The ideal root canal treatment depends on various essential factors such as proper chemo-mechanical preparation, obturation, and post endodontic restoration. The aim of this treatment is to eliminate microorganisms and any future predilection of re-infection. Proper seal is required to prevent any chance of proliferation of bacteria and future occurrence of any pathology. Sealer along with solid obturating material acts synergistically to create hermetic seal ${ }^{(1)}$.While 'gutta-percha

1. Lecturer of Endodontics, Faculty of Dental Medicine, Al-Azhar University (Assuit Branch) - Egypt.

2. Lecturer of Endodontics, Faculty of Dental Medicine, Al-Azhar University, Cairo, Egypt. 
root fillings' remained the household term, it was realized that in the absence of a sealing cement, such root fillings were frequently associated with clinical and radiographic signs of apical periodontitis. Therefore, developments in endodontic materials have been mainly on the chemistry and properties of the sealer as a technically and biologically important part of the root filling ${ }^{(2)}$.

A sealer is basically used to fill the irregularities of the root canal system, bond the core material to the root canal walls, and serve as a lubricant. An ideal root canal sealer should be biocompatible, antibacterial, nontoxic, and radiopaque, and it should also hermetically seal the root canal system, be dimensionally stable, and should have good adhesion to the root canal wall ${ }^{(3,4)}$.

Recently, adhesive obturation systems have been introduced in endodontics in an attempt to obtain a "monoblock" in which the core material, sealing agent and root canal dentin form a single cohesive unit within the root canal ${ }^{(5)}$. Increased adhesive properties to dentin might lead to greater strength of the restored tooth, which may provide greater resistance to root fracture and clinical longevity of an endodontically treated tooth ${ }^{(6)}$. Recent advances in adhesive technology have led to the introduction of a new generation of endodontic sealers and filling materials that are based on adhesive properties and polymer resin technology. These materials are capable of bonding to radicular dentin by forming a hybrid layer and penetrating deep into dentinal tubules by their hydrophilic properties ${ }^{(7)}$.

The push-out test can be used to measure the interfacial shear strength developed between different surfaces, providing additional information on the evaluation of adhesion properties. The test intends to assess to which extent the sealer and the core material are bonded together into a solid mass as well as the strength of the bond to the canal wall. Thus, its results can be useful for inferring the stress suffered during post space preparation ${ }^{(8-10)}$.So this study was directed to evaluate dentin bond strength by push-out test of three root canal sealers (IRoot SP, AH Plus, and MTA Fillapex endodontic sealers) with cold lateral obturation technique using pushout test.

\section{MATERIALS AND METHODS}

\section{Teeth selection:}

A total of 57 freshly extracted mandibular premolar teeth with straight, mature fully developed, single root canals and anatomically similar dimensions with rounded canal cross section were collected from the out-patient clinic of Oral Surgery Department, Faculty of Dental Medicine, Al-Azhar University (Assuit branch). Only those teeth with fully formed apices were selected, whereas, roots with resorption defects, fractures or open apices were excluded. Extracted teeth washed out with running water. A solution of $5.25 \%$ sodium hypochloride (Naocl) soaked into gauze was used to remove any soft tissue covering. The root surface and any calculus was removed by ultrasonic scalar (Wood peaker, China) and rinsed with running water for one minute .The selected teeth were stored in a jar filled with $10 \%$ natural buffered formalin at room temperature ${ }^{(11)}$.

\section{Specimen preparation:}

The crown of each tooth was removed by using safe side diamond disk (Brasseler, U.S.A) mounted in low speed hand piece (NSK, Japan) under copious flow of water to standardize the length of all roots nearly $16 \pm 1 \mathrm{~mm}$. Each root canal was explored with \# 10k file (Dentsply Maillefer, Ballaigues, Switzerland) which was advanced into the canal until passage from the apical foramen just to check the patency of the canal.

\section{Root canal preparation:}

Working length was determined by subtracting 1 $\mathrm{mm}$ from a \# $15 \mathrm{~K}$ file just visible at the apical foramen and the length was recorded. 
The roots were prepared using hand stainless steel K-files taper 0.02 with step back technique up to master apical file \#40. Coronal 2/3 of the canal was then prepared by stainless steel $\mathrm{H}$-hand file larger than the last file used in step back up to \#80 which was used for flaring the canal in circumferential filing motion. $2 \mathrm{ml}$ of $\mathrm{NaOCl}$ of $2.5 \%$ concentration was the irrigant solution used after each file. The specimens received a final rinse with $1 \mathrm{ml}$ 17\% EDTA solution (Dentsply, Latin America, Brazil) in order to remove the smear layer then the root canals were finally flushed with $3 \mathrm{ml}$ distilled water.

\section{Specimens grouping:}

The specimens were divided randomly into three groups (19 teeth each) according to the type of sealers used in this study:

- Group 1: obturated with IRoot SP (IBC, Canada) with qutta percha taper 0.02 cold lateral obturation technique.

- Group 2: Obturated with AH Plus sealer (Dentsply Detrey, GmbH, 78467, Konstanz, Germany) with qutta percha taper 0.02 (Diadent, Korea) cold lateral obturation technique.

- Group 3: Obturated with MTA Fillapex sealer (Angelus Londrina, Brazil) with qutta percha taper 0.02 cold lateral obturation technique.

\section{Specimens' obturation:}

In all groups, obturation was done with cold lateral compaction technique using 0.02 taper gutta percha. Each sealer in each group was mixed according to manufacture instruction, and the obturation was completed with \# 40 gutta percha taper 0.02 cones as master cone. Accessory gutta-percha cones (\# 20 taper 0.02 gutta-percha) were then added until a spreader \# 20 could not be inserted beyond the coronal one third of the canal. A heated instrument was used to cut the gutta-percha cones at canal orifice level and the coronal mass was compacted using a plugger.
All specimens were kept moist by keeping them in gauze moistened with sterile saline solution, and were incubated for 7 days at $37{ }^{\circ} \mathrm{C}$ with $100 \%$ humidity ${ }^{(12)}$.

\section{Push-out bond strength test:}

The roots were vertically positioned and centered in cold cured clear acrylic resin blocks (Acrostone Co., industrial zone, $15 \mathrm{~km}$ northwest of Cairo, Egypt). Each root was sectioned horizontally using a circular diamond disk at low speed with constant fresh cooling water. Sectioning was carried out in horizontal plane perpendicular to the long axis of the main canal. Three sections of $2 \mathrm{~mm}$ thickness were obtained at 3,7 and $11 \mathrm{~mm}$ from the apex to represent apical, middle and coronal third respectively (Fig. 1). The coronal surface of each section was coded and exact thickness of each slice was measured with a digital caliper ${ }^{(13)}$.

Each root slice was mounted in custom made loading fixture [metallic block with circular cavity at the middle, this cavity for specimen housing having a central whole to facilitate displacement of extruded filling material], then subjected to compressive loading at a crosshead speed of $1 \mathrm{~mm} / \mathrm{min}$ via a computer controlled materials testing machine (Fig. 2).

Load applied by using a plunger of $0.9 \mathrm{~mm}$ diameter, where the plunger tip was sized and positioned to touch only the filling, without stressing the surrounding dentin, in apical coronal direction to push the filling toward the larger diameter, thus avoiding any limitation to the filling movement possibly owing to the canal taper. Accordingly, it was guaranteed that the overlaying dentin was sufficiently supported during the loading process.

The maximum failure load was recorded in newtons $(\mathrm{N})$ and converted into megapascals $(\mathrm{MPa})$. The bond strength was calculated from the recorded peak load divided by the computed surface area as calculated by the following formula: 
$\left[\mathrm{A}=\left(3.14 \mathrm{x} \mathrm{r}^{1} \mathrm{X} 3.14 \mathrm{x} \mathrm{r}^{2}\right) \mathrm{L}\right]$

Where $\mathrm{r}^{1}$ apical radius, $\mathrm{r}^{2}$ coronal one, $\mathrm{L}=\left[(\mathrm{r} 1-\mathrm{r} 2) 2+\mathrm{h}^{2}\right]^{0.5}$ and $\mathrm{h}$ is the thickness of the sample in millimeters].

Failure manifested by extrusion of filling piece and confirmed by sudden drop along load-deflection curve recorded by Nexygen computer software. The push-out bond strength was determined for each root slice. Values were recorded, tabulated for each group and statistically analyzed.

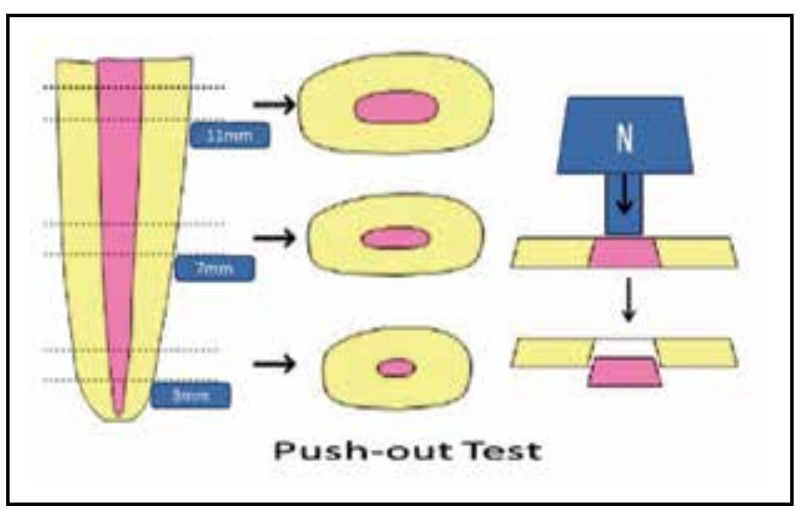

Fig. (1) Schematic drawing showed 3 sections of $2 \mathrm{~mm}$ thickness was obtained at 3,7 and $11 \mathrm{~mm}$ from the apex to represent apical, middle and coronal thirds.

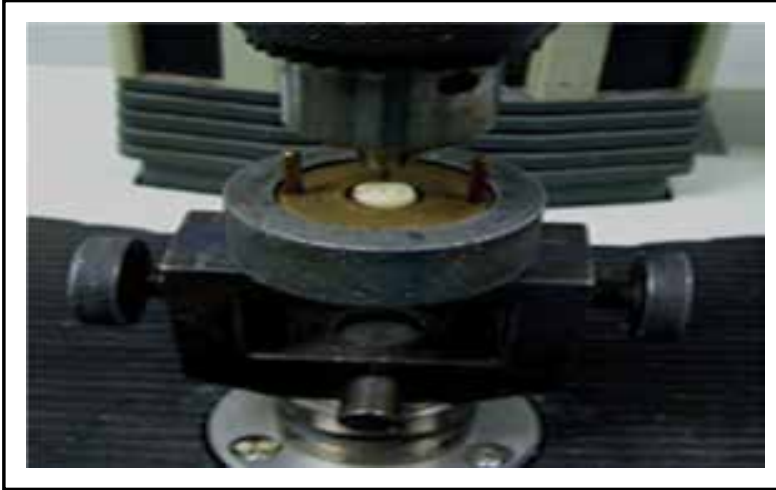

Fig. (2) A photograph showing push-out bond strength test specimen mounted on materials testing machine.

\section{Statistical Analysis}

The data were collected; mean and standard deviation (SD) of push-out bond strength for each group were calculated. Statistical analysis was performed using one-way analysis of variance (ANOVA).
The significance level was set at $\mathrm{P} \leq 0.05$. Statistical analysis was performed with IBM SPSS Statistics Version 20 for Windows.

\section{RESULTS}

1. The mean and standard deviation of push-out bond strength for the three tested sealers were presented in Fig. (3), and Table (1). IRoot SP (Group 1) showed the highest mean value of push-out bond strength (7.3 \pm 0.2$)$, while MTA Fillapex (Group 3) showed the lowest mean value of push-out bond strength $(2.9 \pm 0.3)$.

2. There was statistically significant difference between MTA Fillapex and the other two sealers (IRoot SP, And AH Plus) where P-value = 0.001.whereas, there was no statistically significant difference between IRoot SP, and AH Plus sealers where $\mathrm{P}$-value $=0.06$.

Table (1): The mean, standard deviation (SD) values of push-out bond strength.

\begin{tabular}{|c|c|c|}
\hline Sealer & $\begin{array}{l}\text { Push-out bond strength } \\
\text { Mean } \pm \text { SD }\end{array}$ & P-value \\
\hline IRoot SP & $7.3 \pm 0.2$ & \multirow{2}{*}{$0.06^{\mathrm{ns}}$} \\
\hline AH Plus & $6.8 \pm 0.1$ & \\
\hline MTA Fillapex & $2.9 \pm 0.3$ & $0.001 *$ \\
\hline
\end{tabular}

$*$; significant $(P \leq 0.05) \quad n s ;$ non-significant $(p>0.05)$

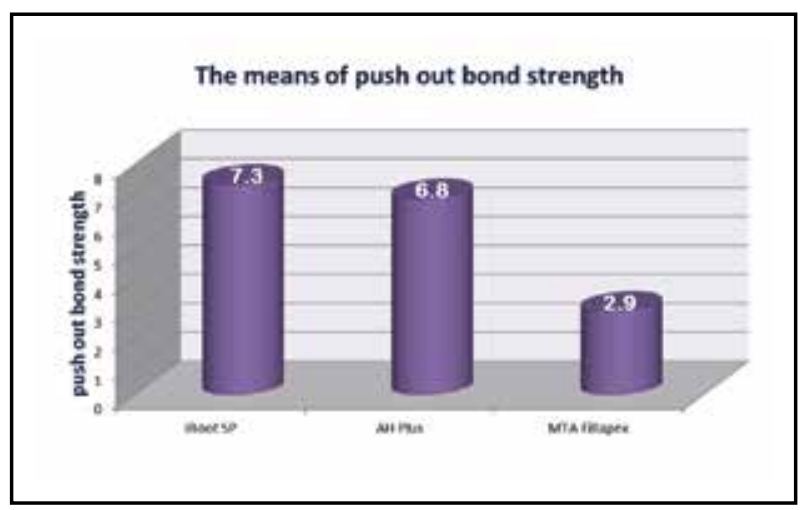

Fig. (2) A histogram showing the mean and standard deviation of push-out bond strength of IRoot SP, AH Plus and MTA Fillapex groups. 


\section{DISCUSSION}

Adhesion to the root canal dentin is one of the necessary characteristics of endodontic sealers for two reasons: the superior seal which in turn results in less leakage ${ }^{(14)}$ and prevention of the dislodgment of the filling material during restorative procedures ${ }^{(15)}$.The present study was designed to evaluate dentin bond strength by push-out test of IRoot SP, AH Plus, and MTA Fillapex endodontic sealers with cold gutta- percha lateral obturation technique using push-out test.

The push-out test was used because it has become a widely accepted method for recording the interfacial bond strength of endodontic materials to root dentin, even at low levels ${ }^{(16)}$. Regarding this study, standardization of the experimental groups was done. Human freshly extracted mandibular premolars with approximately similar apical diameters (\# \#20) and similar root length $(16 \pm 1 \mathrm{~mm})$ and rounded canal cross section were selected. The teeth were collected in jar filled with $10 \%$ formalin that storage of teeth by freezing, or in media such as neutral buffered formalin, chloramine, and distilled water, did not significantly affect the shear bond strength of the resin to dentin ${ }^{(17)}$.

Hand instrumentation technique was used to prepare the root canals because it is still widely used throughout the world ${ }^{(18)}$. Smear layer was removed with $1 \mathrm{ml}$ of $17 \%$ EDTA used for $1 \mathrm{~min}$ which increase the penetration of the sealer into the dentinal tubules, and its mechanical interlocking to the canal walls $^{(6)}$. The root canals were finally flushed with 3 $\mathrm{ml}$ distilled water to remove the negative effect of $\mathrm{NaOCl}$ on shear bond strength of resin-based sealers to dentin ${ }^{(19)}$.

The result showed that IRoot SP (Group 1) showed the higher mean value of push-out bond strength, followed by AH Plus (Group 2) while MTA Fillapex (Group 3) showed the lowest mean value of push-out bond strength .This might be attributed to some inherent properties of the IRoot SP including the calcium silicate composition, which helps minimize shrinking during setting, and the extremely small particle size and level of viscosity, which enhance flow into dentinal tubules, may have enhanced its bonding effectiveness to root canal dentin, resulting in increased dislocation resistance ${ }^{(20,21)}$.

According to the present results, the epoxy resin based sealer (AH plus) showed significantly high dislocation resistance than the mineral trioxide aggregate-based sealers (MTA Fillapex), ranking second among the sealers tested. This result corroborates those of previous studies showing that the epoxy resin-based sealer had significantly higher bond strength to radicular dentin than the tested mineral trioxide aggregate-based sealers ${ }^{(22,23)}$.

The results obtained with the epoxy-resin based sealer may be associated with its low shrinkage during the setting phase, as well as its long-term dimensional stability, better penetration into the micro-irregularities because of its creep capacity and long setting time, which increases the mechanical interlocking between sealer and root dentin. This fact, allied to the cohesion among sealer molecules, increases the resistance to removal and/or displacement from dentin, which can be translated as greater adhesion ${ }^{(24-26)}$. These results were in agreement with previous study comparing bond strength of a calcium silicate-based sealer tested in bulk or with different main core materials, and showed that IRoot $\mathrm{SP}$ and AH plus showing a high dislodgement resistance in push-out test than of MTA Fillapex ${ }^{(27)}$.

It has been suggested that the release of calcium and hydroxyl ions from the set MTA will result in the formation of apatites as the material comes into contact with phosphate-containing fluids ${ }^{(28)}$. It has been reported that the apatite formed by MTA is deposited within collagen fibrils, promoting controlled mineral nucleation on the dentin, seen as the formation of tag-like structures ${ }^{(29)}$. The reason for the low bond strength of MTA Fillapex to the dentin has been attributed to low adhesion capacity of these tag-like structures. 


\section{CONCLUSION}

Within the limitations of this study,it can be concluded that IRoot SP and AH plus sealers had greater resistance to push-out than MTA Fillapex sealer.

\section{REFERENCES}

1. Tyagi S, Mishra P, Tyagi P. Evolution of root canal sealers: An insight story. Eur J Gen Dent 2013 ;(2): 199-218.

2. Qrstavik D. Materials used for root canal obturation: technical, biological and clinical testing. Endo Topics, 2005 ; (12): 25-38.

3. Gomes-Filho JE, Watanabe S, Bernabe' PFE, Bernabé P, Costa M. A mineral trioxide aggregate sealer stimulated mineralization. J Endod 2009; (35):256-60.

4. Siqueira Jr., Fraga RC and Garcia PF: Evaluation of sealing ability, $\mathrm{PH}$ and flow rate of three calcium hydroxide based sealers. Endod Dent Traumatol 1995; 11(5): 225-8.

5. Fisher MA, Berzins DW, Bahcall JK. An in vitro comparison of bond strength of various obturation materials to root canal dentin using a push-out test design. J Endod 2007; 33(7):856- 8.

6. Schwartz RS. Adhesive dentistry and endodontics. Part 2: bonding in the root canal system-the promise and the problems: a review. J Endod 2006; 32(12):1125-34.

7. Pameijer $\mathrm{CH}, \mathrm{Zmener} \mathrm{O}$. Resin materials for root canal obturation. Dent Clin North Am 2010; 54(2):325-44.

8. Thompson JI, Gregson PJ, Revell PA. Analysis of push-out test data based on interfacial fracture energy. J Mater Sci Mater Med 1999; (10):863-8.

9. Chandra $\mathrm{N}$ and Ghonem H. Interfacial mechanics of pushout tests: theory and experiments. Composites Part A: Applied Science and Manufacturing 2001; (32):575-84.

10. Qrstavik D, Eriksen HM, Beyer-Olsen EM. Adhesive properties and leakage of root canal sealers in vitro. Int Endod J 1983; (16):59-63.

11. William V, Burrow MF, Palamara JE, Messer LB. Microshear bond strength of resin composite to teeth affected by molar hypo-mineralization using 2 adhesive systems. Pediatr Dent 2006; 28(3):233-41.

12. Graziele MM, Kuga MC, Regina V K, VazquezG, Aranda AJ, Faria-Junior NB, et al. Evaluation of the interaction between sodium hypochlorite and several formulations containing chlorhexidine and its effect on the radicular dentin e SEM and push-out bond strength analysis. Microsc Res Tech 2014; 77(1):17-22.
13. Patil SA, Dodwad PK, Patil AA. An in vitro comparison of bond strengths of gutta-percha/AH plus, resilon/epiphany self-etch and EndoREZ obturation system to intraradicular dentin using a push-out test design. J Conserv Dent 2013; 16(3): 238-42.

14. Saleh IM, Ruyter IE, Haapasalo MP, ,Orstavik D. Adhesion of endodontic sealers: scanning electron microscopy and energy dispersive spectroscopy. J Endod 2003; (29):595-601.

15. Haffman BP, Mai S, Pinna L, et al. Dislocation resistance of ProRoot Endo Sealer, a calcium silicate-based root canal sealer, from radicular dentin. Int Endod J. 2009; (42):34-46.

16. Cecchin D, Souza M, Carlini-Junior B, Barbizam JV. Bond strength of resilon/epiphany compared with gutta-percha and sealers Sealer 26 and Endo Fill. Aust Endod J 2012; 38(1):21-5

17. Titley KC, Chernecky R, Rossouw PE, Kulkarni GV. The effect of various storage methods and media on shear-bond strengths of dental composite resin to bovine dentine. Arch Oral Biol 1998; 43(4):305-11.

18. Mahdi AA, Bolanos-Carmona V, Gonzalez-Lopez S. Bond strength to root dentin and fluid filtration test of AH Plus/ guttapercha, EndoREZ and RealSeal systems. J Appl Oral Sci 2013; 21(4):369-75.

19. Bohn S, Ilie N. Wetting behavior of silicone- and resinbased root canal sealers. Int Endod J 2014; 47(6):542-9.

20. Zhang W, Li Z and Peng B. Assessment of a new root canal sealers apical sealing ability. Oral Surg Oral Med Oral Pathol Oral Radiol Endod 2009; 107(6): 79-82.

21. Shokouhinejad N, Gorjestani H, Nasseh AA, Hoseini A, Mohammadi M and Shamshiri AR. Push-out bond strength of gutta-percha with a new bioceramic sealer in the presence or absence of smear layer. Aust Endod J 2013; (39): 2-6.

22. Nagas E, Uyanik M, Eymirli A. Dentin Moisture Conditions Affect the Adhesion of Root Canal Sealers. J Endod 2012; (38):240-4.

23. Guiotti FA, Kuga MC, Duarte MA, Sant'anna A, Júnior and Faria G. Effect of calcium hydroxide dressing on push-out bond strength of endodontic sealers to root canal dentin. Braz Oral Res 2014; 28(1(:1-6.

24. Pommel L,About I, Pashley D and Camps J.Apical leakage of four endodontic sealers. J Endod 2003; 29(3):208-10. 
25. Schafer E, Zandbiglari T. Solubility of root-canal sealers in water and artificial saliva. Int Endod J 2003; 36(10):660-9.

26. Nunes VH, Silva RG, Alfredo E, Sousa-Neto MD and Silva-Sousa YT. Adhesion of Epiphany and AH Plus sealers to human root dentin treated with different solutions. Braz Dent J 2008; 19(1):46-50.

27. Nagas E, Cehreli Z, Uyanik M and Durmaz V. Bond strength of a calcium silicate based sealer tested in bulk or with different main core materials. Braz Oral Res. 2014; 28(1):1-7.

28. Sarkar NK, Caicedo R, Ritwik P, Moiseyeva R, Kawashima I. Physicochemical basis of the biologic properties of mineral trioxide aggregate. J Endod 2005; (31):97-100.

29. Reyes-Carmona JF, Felippe MS, Felippe WT. Bio mineralization ability and interaction of mineral trioxide aggregate and white Portland cement with dentin in a phosphate containing fluid. J Endod. 2009; (35):731-6. 